\title{
Avaliação de um curso para a capacitação dos profissionais da enfermagem na urgência e emergência
}

\author{
Evaluation of a course for the training of nursing professionals in urgency and emergency
}

\author{
Thaisa Vieira Sonnberger $\mathbb{D}^{1} \bowtie$, Gustavo Lenci Marques $(\mathbb{D} 1$, Flavia Klas Blanski Pinheiro $(\mathbb{D} 1$ \\ ${ }^{1}$ Universidade Federal do Paraná, Setor de Ciências da Saúde. Curitiba, Paraná, Brasil.
}

Como citar este artigo (How to cite this article):

Sonnberger TV, Marques GL, Pinheiro FKB. Avaliação de um curso para a capacitação dos profissionais da enfermagem na urgência e emergência (Evaluation of a course for the training of nursing professionals in urgency and emergency). Sci Med. 2019;29(3):e34203. https://doi.org/10.15448/1980-6108.2019.3.34203

\section{RESUMO}

OBJETIVO: Esse trabalho visa avaliar um modelo de curso para a capacitação da equipe de enfermagem no atendimento de urgências e emergências, estabelecendo o período pelo qual o conhecimento adquirido no curso é memorizado e o prazo em que deveria ser reaplicado para garantir a proficiência.

MÉTODOS: Foram selecionados 45 profissionais da enfermagem que atuavam nas unidades de cardiologia e aplicado um pré-teste de 20 questões de múltipla escolha, avaliando o conhecimento prévio da equipe. Após o pré-teste, ministrou-se um curso teórico-prático presencial acerca do reconhecimento de pacientes críticos e manejo inicial de uma parada cardiorrespiratória, praticando as manobras de reanimação em um manequim. Após o curso era reaplicado o mesmo teste para identificar se houve melhora no número de acertos. Dentro de três e seis meses o teste foi novamente aplicado, a fim de estabelecer a taxa de memorização do conhecimento no período.

RESULTADOS: Observamos que a média de acertos no pré-teste foi de 9,4 $\pm 3,3$ questões. No pós-teste imediato houve um aumento da média de acertos para 15,3 \pm 2 questões. Após três meses, o número médio de acertos caiu para $12 \pm 3,1$ questões e transcorridos seis meses foi de $10 \pm 3,3$ questões. Foi possível identificar ainda que os profissionais que atuavam na Unidade de Cuidados Intensivos e Hemodinâmica apresentaram um maior número de acertos $(12,6 \pm 3,42)$ quando comparados com os profissionais que atuavam na Enfermaria $(9,4 \pm 4,4)$. Realizando uma análise regressiva, observamos uma melhora estatisticamente significativa nos resultados dos testes logo após o treinamento e em três meses $(\mathrm{p}<0.05)$ - o que não ocorreu em seis meses.

CONCLUSÃO: Podemos inferir a partir da melhora no número de acertos que o modelo de curso teórico-prático presencial foi efetivo em promover a capacitação dos profissionais da enfermagem. No entanto, a fixação do conhecimento decai ao longo dos meses, retornando a valores próximos do inicial em seis meses.

DESCRITORES: Reanimação Cardiopulmonar, Capacitação, Equipe de Enfermagem, Parada Cardíaca, Gestão de Conhecimento.

\section{ABSTRACT}

AIMS: This work aims to evaluate a course model for the training of the nursing team in emergency care, as well as establishing the period which the knowledge acquired in the course is still memorized and when the course should be reministered to guarantee the professional's proficiency.

METHODS: We selected 45 nursing professionals who worked at the Cardiology Units of the Hospital de Clínicas of the Federal University of Paraná. In this group, a pre-test of 20 multiple choice questions was applied, mentioning the previous knowledge of the team. After the pre-test, a two-hour theoretical-practical course was given on the recognition of severe patients and initial management of a cardiorespiratory arrest, practicing ventilation maneuvers and chest compression on a manikin. After the course, the same test was reapplied to identify if there was improvement in the number of correct answers. Within three and six months the test was again applied in order to establish the knowledge storage rate over that period.

RESULTS: We observed that the average accuracy in the pre-test was $9.4 \pm 3.3$ questions. In the immediate post-test, there was an increase in the mean of correct answers to $15.3 \pm 2$ questions. After three months, the average number of correct answers fell to $12 \pm 3.1$ questions and after six months was $10 \pm 3.3$ questions. It was also possible to identify that the professionals who worked in the Intensive Care Unit and Hemodynamics presented a greater number of correct answers (12.6 \pm 3.4$)$ when compared to the professionals who worked in the Infirmary (9.4 \pm 4.4). Performing a regressive analysis, we observed a statistically significant improvement in the test results shortly after the training and in three months $(\mathrm{p}<0.05)$ - which did not occur in the time of six months.

CONCLUSION: We can infer from the improvement in the number of correct answers to the questionnaire that the theoretical-practical course model was effective in promoting the training of nursing professionals. However, the fixation of knowledge decays over the months, returning to values close to the initial within six months

KEYWORDS: Cardiopulmonary Resuscitation, Training, Nursing Team, Heart Arrest, Knowledge Management. 
Abreviaturas: PCR, Parada cardiorrespiratória; RCP, Reanimação cardiopulmonar; UFPR, Universidade Federal do Paraná.

\section{INTRODUÇÃO}

A Organização Mundial da Saúde estimou que em 2018 44\% das mortes documentadas decorreram de doenças cardiovasculares, a principal causa de morte entre as doenças não infecciosas, totalizando 17,9 milhões de casos no mundo [1]. Para a redução dessa mortalidade, a proficiência no atendimento de emergências cardiovasculares é essencial. A reanimação cardiopulmonar (RCP), quando realizada de maneira adequada, é uma alternativa eficiente para a melhora da sobrevida e do prognóstico dos pacientes em situação de emergência cardiovascular [2,3].

Os primeiros minutos de uma parada cardiorrespiratória (PCR) são primordiais no sucesso da reanimação $[4,5]$. O reconhecimento precoce dos sinais de PCR, uma resposta rápida de profissionais capacitados e a qualidade das compressões torácicas aliadas a uma desfibrilação precoce - são os principais fatores prognósticos na recuperação do paciente [5-8]. Cerca de $40 \%$ das PCRs ocorrem no ambiente intrahospitalar e as falhas no atendimento à PCR são associadas a fatores humanos em $40 \%$ dos casos [4, 6]. A equipe de enfermagem, por estar mais próxima ao leito, costuma ser a primeira a identificar pacientes críticos e situações de risco, o que torna essencial sua aptidão para iniciar os atendimentos de emergência [3]. Espera-se, portanto, que os profissionais da enfermagem estejam aptos a coordenar uma equipe de atendimento de emergência, planejando o cuidado e atuando diretamente nos procedimentos de reanimação [6].

Desde o fim a década de 80 , as habilidades e os conhecimentos necessários para a realização da RCP passaram a ser objeto de estudo, tentando estabelecer melhores métodos para capacitação dos profissionais de saúde. Diversos trabalhos analisaram a eficácia do treinamento de reanimação e destacaram o fato de que as habilidades e os conhecimentos decaem ao longo do tempo [9]. Historicamente, o treinamento de RCP deve ser oferecido bienalmente através das certificações como o Basic Life Support. No entanto, evidências mais recentes sugerem que essa frequência de treinamento pode não ser a ideal $[3,5-8,10]$.

Uma grande revisão da literatura, focada no treinamento simulado de habilidades cirúrgicas, identificou que a simulação era altamente eficaz para a proficiência dos profissionais, garantindo ainda a segurança do paciente, mas que as habilidades também eram perdidas ao longo do tempo, assim como acontece com as habilidades clínicas [11].

Nesse sentido, o objetivo deste trabalho é identificar um modelo de curso apropriado para capacitar a equipe de enfermagem em RCP e identificar o período pelo qual o conhecimento adquirido ainda está memorizado e disponível para a prática clínica, estabelecendo o prazo em que o curso deveria ser reaplicado para garantir a proficiência dos profissionais.

\section{MATERIAIS E MÉTODOS}

Esse estudo foi elaborado com um desenho longitudinal prospectivo intervencionista. Formulouse um questionário de 20 questões de múltipla escolha, com a intenção de avaliar o conhecimento prévio da equipe. Após a aplicação do questionário, ministrouse um curso teórico-prático presencial acerca do reconhecimento de pacientes graves e manejo inicial de uma PCR. Após o curso, era reaplicado o mesmo questionário para identificar se houve melhora no número de acertos. Dentro de três e seis meses o questionário foi novamente aplicado, avaliando a memorização do conhecimento adquirido ao longo desse período.

\section{Questionário}

A fim de avaliar o conhecimento prévio da equipe e se houve melhora após o treinamento, os pesquisadores envolvidos na pesquisa elaboraram um questionário de 20 questões de múltipla escolha com cinco opções de respostas, sendo apenas uma correta, com base nos protocolos mais utilizados $[12,13]$. Aplicou-se o questionário primeiramente em acadêmicos de medicina voluntários para identificar possíveis ambiguidades ou dúvidas nas questões, que foram então ajustadas para melhor compreensão e interpretação. O questionário contava ainda com uma sessão de perguntas sobre o tempo que cada profissional havia dispendido em sua formação, há quanto tempo havia realizado o último treinamento ou capacitação em RCP e se o profissional se considerava seguro para a realização dos procedimentos de RCP.

$\mathrm{O}$ questionário foi aplicado em um primeiro momento, recebendo o nome de pré-teste, ao longo de uma semana em todas as Unidades de Cardiologia do Hospital de Clínicas da Universidade Federal do Paraná (UFPR) - Unidade de Cuidados Intensivos, Hemodinâmica e Enfermaria - em toda a equipe de 
enfermagem presente, totalizando 45 pessoas. Orientou-se os profissionais que a participação no estudo era voluntária e coletou-se o termo de consentimento livre e esclarecido. Questões não assinaladas ou assinaladas mais de uma vez foram consideradas como incorretas.

\section{Intervenção}

Ao fim do pré-teste ministrou-se um curso teóricoprático presencial de metodologia ativa por um médico cardiologista, uma médica residente do serviço de cardiologia e uma acadêmica de medicina, com base nas atualizações de 2015 para a realização de RCP da American Heart Association.

Em um primeiro momento, os pesquisadores explicavam oralmente a fisiopatologia de uma PCR e a necessidade de iniciar uma intervenção precoce. A seguir elaborava-se um fluxograma em quadro negro com os passos a serem seguidos durante a reanimação, ordenando todas as etapas e estabelecendo o tempo que poderia ser dispendido em cada uma delas. Durante a construção do fluxograma perguntava-se aos participantes quais seriam os passos a serem seguidos, mantendo uma metodologia ativa durante a explicação teórica. Por fim, com o auxílio de um manequim de média fidelidade os pesquisadores demonstravam os passos da reanimação, praticando as manobras no manequim.

Após a explicação teórica os profissionais eram convidados a praticar os procedimentos de RCP no manequim de média fidelidade. Em todas as ocasiões simulou-se uma situação clínica comum da unidade em que o curso estava sendo ministrado e os profissionais deveriam realizar o atendimento simulado. A carga horária do curso totalizava em média duas horas com equipes de três a cinco pessoas.

Ao final do curso todas as possíveis dúvidas eram esclarecidas e os profissionais eram novamente convidados a responder o mesmo questionário, agora chamado de pós-teste, para verificar qual seria a nova taxa de acerto da equipe. Vale salientar que em nenhum momento corrigiu-se o questionário com os profissionais e que eles não tiveram acesso ao número de acertos que haviam atingido em cada etapa do estudo.

\section{Efeito em longo prazo}

A fim de avaliar o efeito em longo prazo do treinamento, dentro de três e seis meses o questionário foi novamente respondido pelos profissionais que realizaram o curso no primeiro momento. Esses questionários receberam o nome de pós-teste de três e de seis meses. Ao final do estudo, após a aplicação do pós-teste de seis meses, corrigiu-se todo o questionário com os profissionais interessados, esclarecendo as dúvidas que restaram e oferecendo um material digital de atualização contendo as Diretrizes de 2015 da American Heart Association para RCP.

\section{Critérios de inclusão e exclusão}

Incluíram-se no estudo todos os profissionais da enfermagem (enfermeiros e técnicos de enfermagem) das Unidades de Cardiologia do Hospital de Clínicas da UFPR. Os critérios de exclusão do estudo foram: profissionais que realizaram treinamento em RCP há menos de seis meses no início do estudo ou qualquer treinamento durante o estudo, que não o curso oferecido; outros profissionais que não enfermeiros ou técnicos de enfermagem; profissionais que não assinassem o termo de consentimento livre e esclarecido.

Ao longo do seguimento do estudo, alguns profissionais foram excluídos da pesquisa por não trabalharem mais no Hospital de Clínicas da UFPR ou por se recusarem a responder os pós-testes de três e seis meses. Nesses casos, os dados relativos ao préteste e pós-teste foram utilizados, mas excluíram-se os indivíduos da análise de três e seis meses.

\section{Aspectos éticos}

A pesquisa foi aprovada pelo Comitê de Ética de Pesquisa em Seres Humanos do Hospital de Clínicas da UFPR (número do parecer do comitê de ética: 1.948.250) e foi obtido o Termo de Consentimento Livre e Esclarecido de todos os participantes.

\section{Análise dos dados}

A análise dos dados foi realizada pelo software $\mathrm{R}$, versão 3.4.0. Para investigar o número de acertos dos questionários, variável dependente, com relação ao tempo, ao local de trabalho (unidade de cuidados intensivos e hemodinâmicos, classificados como unidade crítica, e enfermaria, classificada como unidade não crítica) e ao tempo dispendido na formação de cada profissional, variáveis independentes, utilizou-se o Modelo de Regressão Marginal Copula Gaussiano $[14,15]$, por se tratar de uma variável quantitativa discreta, assumindo-se a distribuição marginal pós-som.

Para a análise da segurança dos profissionais na realização da RCP, variável dependente de resposta 
ordinal, com relação às mesmas variáveis independentes supracitadas, utilizou-se o método de equações de estimativas generalizadas para dados com respostas ordinais [16]. O intervalo de confiança foi de 95\%.

\section{RESULTADOS}

No total, 45 profissionais de enfermagem preenchiam os critérios de inclusão no estudo e participaram do pré-teste, curso teórico prático e pós-teste, sendo 32 da Unidade Crítica e 13 da Unidade Não-Crítica. Na aplicação do pós-teste de três meses excluíram-se 11 pessoas e no pós-teste de seis meses outras nove pessoas foram excluídas da coleta de dados. Os motivos das exclusões e o número total de participantes em cada etapa são demonstrados na Figura 1.

No pré-teste, a média de respostas corretas foi de 9,4 questões, enquanto no pós-teste, as pontuações aumentaram para 15,3 acertos - o que representou um incremento de $29,7 \%$ no número de acertos. Tanto no subgrupo da unidade crítica como da unidade não crítica houve um aumento de acertos entre o pré e o pós-teste.

Na unidade crítica a média de respostas corretas foi de $12,6 \pm 3,4$ questões (sendo o máximo de 20 e o mínimo de cinco acertos) e na unidade não crítica o número médio de acertos foi de $9,4 \pm 4,4$ questões, com um número máximo de 17 e mínimo de três acertos. $\mathrm{O}$ número de acertos máximo, mínimo e médio e o desvio padrão do pré-teste, pós-teste, pós-teste de três meses e pós-teste de seis meses são descritos na Tabela 1 e o número de acertos por questão em cada etapa do estudo está disponível Figura 2.

Quando se avaliou os dados por análise regressiva, comparando-se a quantidade de acertos no questionário em relação ao tempo transcorrido do treinamento e a unidade (crítica ou não crítica) pôde-se perceber que houve uma melhora estatisticamente significativa $(\mathrm{p}<0,05)$ no número de acertos do pós-teste e do pós-teste de três meses com relação ao pré-teste, independentemente da unidade avaliada. Esses dados podem ser observados na Figura 3. No entanto, na análise do pós-teste de seis meses, mesmo havendo um aumento no número de acertos do questionário com relação ao pré-teste, esse aumento não foi estatisticamente significativo $(\mathrm{p}=0,41)$.

O tempo dispendido na formação de cada profissional também influenciou positivamente o número de acertos no questionário $(\mathrm{p}<0,01)$, sendo que aqueles que levaram mais tempo para concluir sua formação, obtiveram uma maior média de respostas corretas nos questionários em todos os períodos avaliados. O tempo médio de estudo dentre os profissionais analisados foi de 3,8 anos, sendo o mínimo de 1,2 e o máximo de 11 anos.

Quanto à segurança dos profissionais para realização da RCP apenas 11 profissionais que trabalhavam nas unidades críticas sentiam-se totalmente seguros para manejar uma PCR antes de realizar o curso teóricoprático, sendo que 19 consideravam-se parcialmente seguros e dois totalmente inseguros. Na unidade não crítica seis pessoas sentiam-se seguras, seis parcialmente seguras e apenas um inseguro. Imediatamente após a realização do curso os profissionais foram convidados
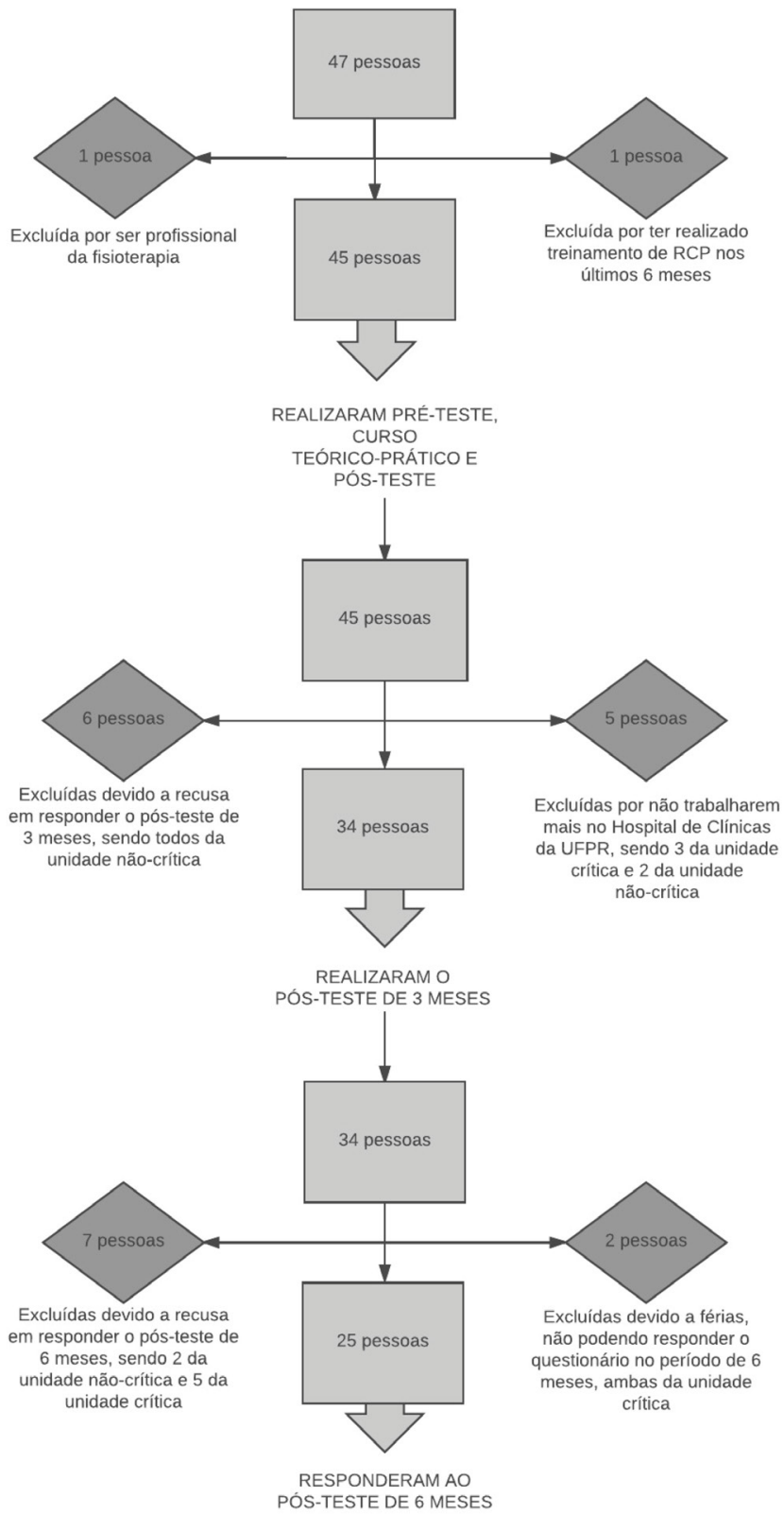

Figura 1. Fluxograma indicando o número de participantes em cada etapa do estudo e os motivos das exclusões ao longo do tempo. 
a responder essa pergunta novamente. Nesse momento, 18 profissionais da unidade crítica e sete da unidade não crítica consideravam-se totalmente seguros. Esses dados são ilustrados na Figura 4.

Utilizando o método de equações de estimativas generalizadas para dados de respostas ordinais encontrou-se que apenas a variável tempo influenciava na segurança da equipe para realização da RCP $(\mathrm{p}<0,05)$. Assim, os profissionais tinham mais chances de considerarem-se seguros nos pós-testes, tanto no imediato (OR 2,10, IC 95\%:1,21;3,65), quanto no de três (OR 2,64, IC95\%:1,07;6,48) e de seis meses (OR 2,46, IC95\%:1,07;5,1). O tempo dispendido na formação de cada profissional (OR 1,01, IC95\%:0,99;1,04) e o local de trabalho (OR 1,42, IC95\%:0,40;5,04) não influenciaram em sua segurança. Apenas seis profissionais haviam realizado um treinamento em RCP nos últimos seis meses a um ano, nove entre um e dois anos e 30 profissionais não haviam realizado nenhum tipo de treinamento nos últimos dois anos.

Tabela 1. Dados relativos ao número de acertos dos questionários do pré-teste, pós-teste, pós-teste de três meses e pós-teste de seis meses.

\begin{tabular}{lcccc}
\hline Acertos & Pré-teste & Pós-teste & $\begin{array}{c}\text { Pós-teste de } \\
\mathbf{3} \text { meses }\end{array}$ & $\begin{array}{c}\text { Pós-teste de } \\
\mathbf{6} \text { meses }\end{array}$ \\
\hline Média \pm DP & $9,4 \pm 3,4$ & $15,4 \pm 2,5$ & $12,0 \pm 3,2$ & $10,1 \pm 3,3$ \\
Máximo & 16 & 20 & 17 & 15 \\
Mínimo & 3 & 9 & 5 & 4 \\
\hline
\end{tabular}

DP: desvio padrão
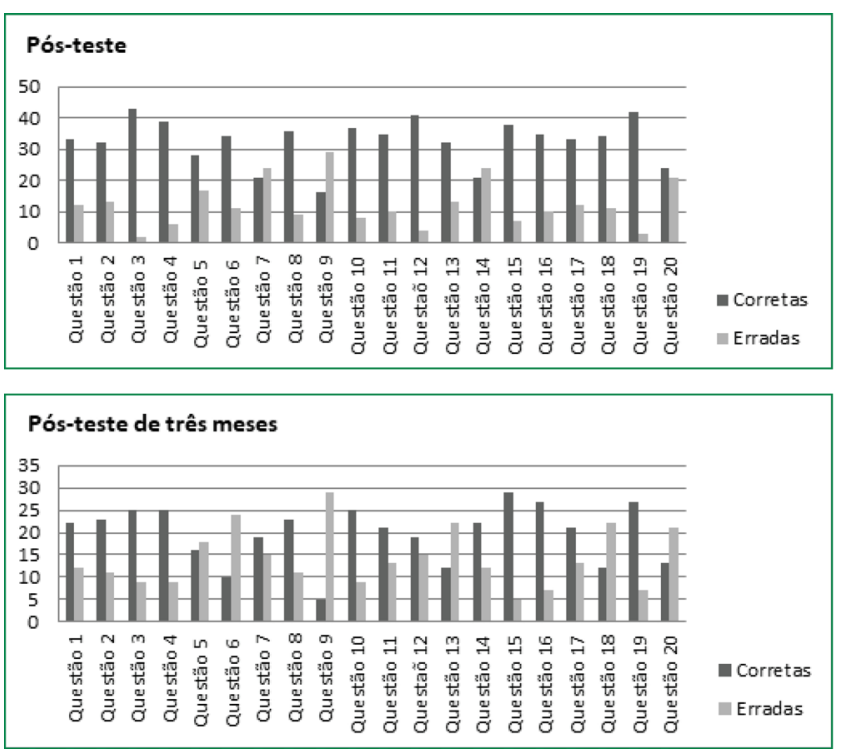

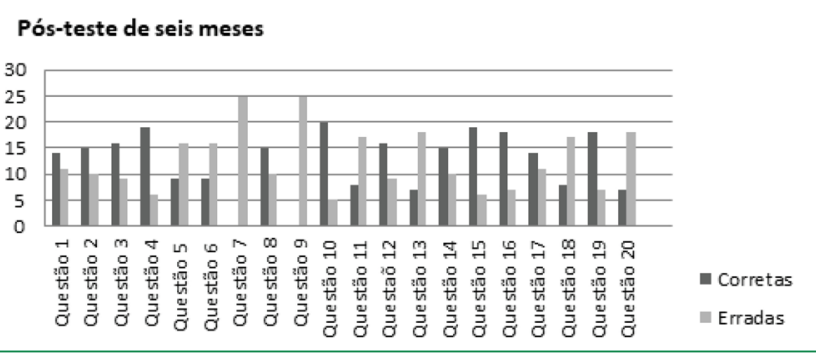

Pré-teste

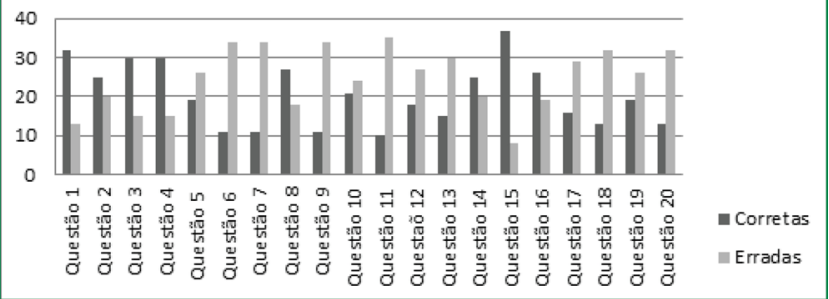

Figura 2. Número de acertos por questão em cada etapa do estudo: pré-teste, pós-teste, pósteste de três meses e pós-teste de seis meses.

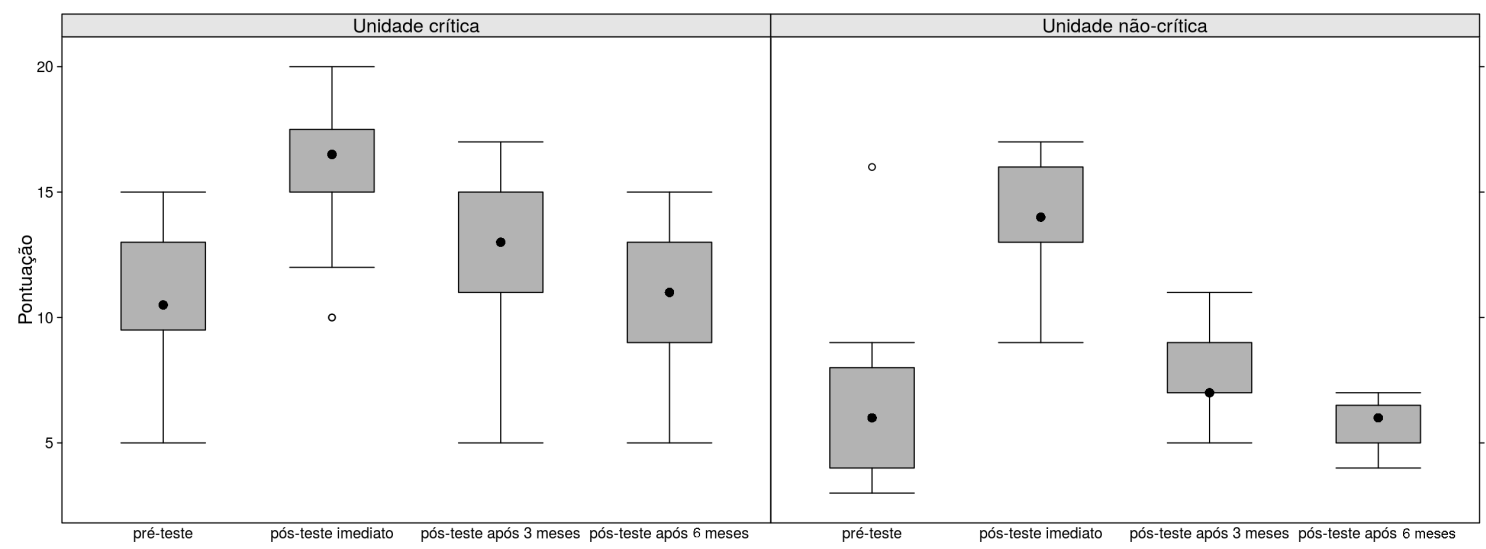

Figura 3. Gráfico ilustrando a diferença entre o número de acertos nos questionários ao longo do estudo, tanto nas unidades críticas como não críticas ( $\mathrm{p}<0,001$ para o pós teste e pós-teste de três meses; $\mathrm{p}=0,411$ para o pósteste de seis meses). 


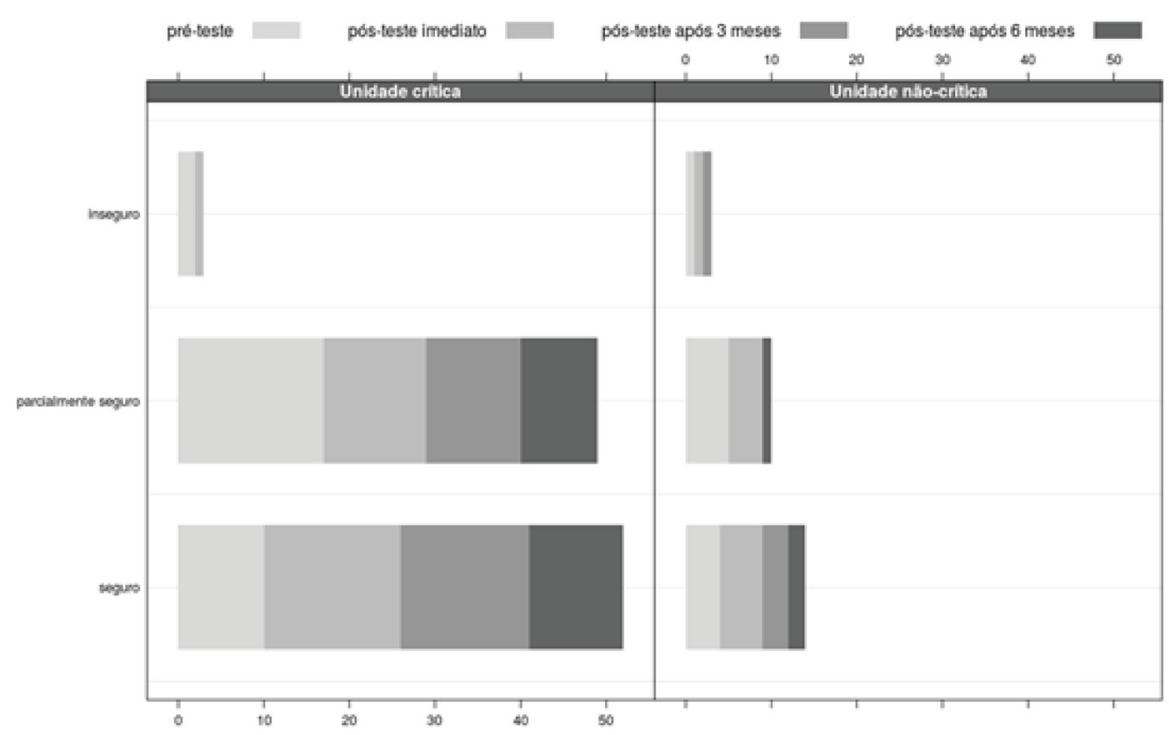

Figura 4. Gráfico demonstrando a segurança dos participantes para a realização dos procedimentos de reanimação cardiopulmonar em cada uma das etapas do estudo.

\section{DISCUSSÃO}

Em nosso estudo a análise inicial que pretendia avaliar a compreensão prévia da equipe de enfermagem a cerca de temas como o reconhecimento do paciente crítico e as manobras básicas de reanimação observou que o conhecimento era inferior ao desejado, com a média de acertos no pré-teste menor do que $50 \%$ das questões.

Esse resultado é compatível com o descrito na literatura visto que pesquisas anteriores indicavam que as habilidades para a realização da RCP e o conhecimento teórico dos profissionais da enfermagem geralmente são abaixo do que se considera ideal - o que poderia ser explicado em parte por atualizações infrequentes ou um treinamento ineficaz em RCP $[5,8]$. Em estudos realizados na Ásia e na Europa os níveis de habilidades da equipe de enfermagem também foram abaixo do esperado devido à falta de treinamento e participação em sessões reais de reanimação, o que costumava melhorar após um curso de capacitação. No entanto, a maioria dos profissionais não realizavam capacitações frequentes $[17,18]$.

Em contrapartida, enfermeiras que participavam de algum treinamento de reanimação registravam uma maior competência e eficácia nas manobras e estavam mais confiantes de suas habilidades [19]. A literatura também identifica os programas de treinamento como capazes de eliminar a ansiedade e aumentar a autoconfiança em lidar com uma PCR [2, 5, 26, 27]. Uma revisão da literatura brasileira indicou ainda que dentre todos os profissionais de saúde treinados por métodos de simulação os enfermeiros eram os maiores beneficiados no que diz respeito à autoconfiança [6].

Com relação à retenção do conhecimento e da habilidade em RCP diversos autores afirmam que ambos decaem ao longo de três e seis meses, sendo que alguns estudos apontam que o único método capaz de possibilitar o conhecimento e a proficiência na realização da RCP em longo prazo é o treinamento dos profissionais a cada três meses, estabelecendo o prazo para a reciclagem dos cursos de capacitação entre 90 e 180 dias $[3,5-8,10]$.

Uma revisão da literatura sobre o tema aborda o chamado efeito de espaçamento dos treinamentos que consiste em múltiplos treinamentos repetitivos ao invés de apenas um treinamento muito abrangente, o que garantiria a proficiência por um período maior. Os autores afirmam que esse método foi validado para diversas áreas de atuação como o método didático mais efetivo em promover a retenção de habilidades e conhecimentos em longo prazo [11].

A literatura sugere ainda que quando a RCP é realizada com pouca frequência, o conhecimento e as habilidades são perdidos em semanas de treinamento. Portanto, nas unidades em que há menos situações de PCR, compatível com as unidades não críticas de nosso estudo, o tempo para a reciclagem da capacitação deveria ser ainda menor [28].

Um estudo brasileiro observou também que os profissionais da enfermagem que atuavam em unidades de tratamento intensivo participavam voluntariamente 
de mais treinamentos de RCP, o que atribuíram ao fato desses profissionais perceberem maior aplicabilidade dos conhecimentos na prática clínica [8]. De maneira semelhante, em nosso estudo as saídas voluntárias da pesquisa foram em sua maioria dos profissionais da unidade não crítica.

Analisando os dados obtidos em nossa pesquisa, com relação ao número de acertos no questionário e a possibilidade de capacitação dos profissionais pelo curso teórico-prático, observamos que a taxa de acertos nos questionários aumentou de maneira significativa entre o pré e o pós-teste (de $47 \%$ para 76,7\%). É notável que o curso teórico-prático utilizando a simulação de média fidelidade teve efeitos benéficos na aquisição do conhecimento da equipe. No entanto, isso não se manteve estável e decaiu nos primeiros três meses, atingindo $60,1 \%$ de acertos no questionário, com piora dos resultados aos seis meses, com apenas 50,4\% de acertos, próximo aos $47 \%$ do pré-teste. Não houve diferença estatísticamente significativa entre a taxa de acertos do pré-teste e do pós-teste de seis meses, o que significa dizer que retornamos aos conhecimentos iniciais transcorridos seis meses da capacitação.

Assim, respondendo ao questionamento inicial de nosso estudo, conseguimos validar o curso teórico-prático presencial com simulação de média fidelidade como um método efetivo de capacitação dos profissionais da enfermagem em RCP, ressaltando que o curso deveria ser novamente aplicado dentro do prazo máximo de seis meses, idealmente entre três e seis meses, intervalo em que o conhecimento retorna aos níveis iniciais.

Apesar de em nosso estudo o conhecimento ter sido aprimorado em todas as unidades após o curso, a média de acertos em todos os períodos avaliados foi menor na unidade não crítica, em geral $16 \%$ menor. No préteste, enquanto a média de acertos na unidade crítica foi de 10,5 questões, a média da unidade não crítica foi de 6,4 questões, o que significa uma diferença de $20 \%$ no conhecimento inicial da equipe. Esse dado também é corroborado pela literatura e atribuído ao fato da equipe de enfermagem das unidades críticas realizarem um maior número de atendimentos com necessidade de RCPs [5].

Quando avaliamos a confiança para a realização da RCP em nosso grupo de estudo, tanto nas unidades críticas como nas não críticas, notou-se um aumento expressivo nos profissionais que se consideravam totalmente seguros após o curso teórico-prático. Eles apresentavam 2,1 vezes mais chances de considerarem-se seguros na realização da RCP logo após o curso, 2,6 vezes mais chances em três meses e 2,4 vezes mais chances em seis meses, independente da unidade de trabalho.

Outro dado que teve um valor preditivo estatisticamente significativo $(\mathrm{p}<0,01)$ no melhor desempenho ao responder o questionário foi o tempo dispendido na formação de cada profissional. Assim, aqueles com um maior tempo de estudo alcançaram maiores médias de acertos em todas as etapas avaliadas, independente da unidade avaliada.

Uma das limitações do nosso estudo foi a avaliação da resposta ao treinamento apenas pelo teste teórico, sem avaliação individual das habilidades práticas, devido a dificuldade de se analisar as habilidades de todos os participantes em manequins ao longo de seis meses. Dessa forma, não foi possível avaliar se a taxa de deterioração do conhecimento teórico decaía na mesma medida que as habilidades práticas, mas alguns estudos sugerem que há uma perda significativa das habilidades de RCP já após oito semanas do treinamento, com uma deterioração correspondente do conhecimento teórico em seis meses [4]. Entretanto, nosso estudo obteve um achado positivo: as questões relativas às habilidades práticas de compressão obtiveram maior taxa de acerto em todas as etapas avaliadas, o que nos leva a crer que o nosso grupo ainda poderia realizar as manobras de reanimação de maneira satisfatória ao longo do período analisado.

Por fim, nossa principal limitação diz respeito à amostra. Devido ao fato do estudo ser prospectivo e a participação voluntária, houve uma perda significativa da amostra inicial até o fim do estudo. Além disso, como a pesquisa foi conduzida nas unidades da Cardiologia do Hospital de Clínicas da UFPR os profissionais envolvidos poderiam apresentar maior experiência com emergências cardiológicas, o que poderia significar um conhecimento inicial acima da média para os profissionais de enfermagem das demais áreas. A escolha dos pesquisadores em iniciar o treinamento com a equipe da cardiologia foi justamente pela importância dessa capacitação, visto o número de pacientes que poderiam se beneficiar de uma RCP de qualidade nesse setor. Mesmo assim, acreditamos que o estudo apresente validade interna e externa, pois, mesmo com uma amostra específica possivelmente experiente em cardiologia, nossos resultados foram compatíveis com os obtidos por estudos de diversos países, envolvendo equipes de enfermagem de vários setores.

O treinamento de ressuscitação cardiopulmonar para a equipe de enfermagem é uma questão complexa e a literatura apresenta muitas sugestões para melhorar a aprendizagem e o desempenho das habi- 
lidades [6,9,11,27]. Nossos dados foram capazes de confirmar que o curso teórico-prático presencial utilizando a simulação de média fidelidade é eficaz na capacitação da equipe de enfermagem em RCP e que o prazo para reministrar o curso deve ser de seis meses, idealmente entre três e seis meses.

\section{AGRADECIMENTOS}

Os autores agradecem a toda a equipe do Serviço de Cardiologia do Hospital de Clínicas da Universidade Federal do Paraná, tanto pela participação no estudo, quanto pelo apoio, incentivo e contribuição com o espaço físico e material para realização do treinamento que possibilitou o desenvolvimento dessa pesquisa.

\section{NOTAS}

Parte deste trabalho é resultado de trabalho de conclusão de curso de Medicina de um dos autores

\section{Apoio financeiro}

Este estudo não recebeu apoio financeiro de fontes externas.

Declaração de conflito de interesses

Os autores declaram não haver conflitos de interesses relevantes ao conteúdo deste estudo.

Contribuições dos autores

Todos os autores fizeram contribuições substanciais para concepção, ou delineamento, ou aquisição, ou análise ou interpretação de dados; e redação do trabalho ou revisão crítica; e aprovação final da versão para publicação.

Disponibilidade dos dados e responsabilidade pelos resultados

Todos os autores declaram ter tido total acesso aos dados obtidos e assumem completa responsabilidade pela integridade destes resultados.

\section{REFERÊNCIAS}

1. World health statistics 2018: monitoring health for the SDGs, sustainable development goals. Geneva: World Health Organization; 2018. [updated 2019 April; cited 2019 April 13]. Available from: https://apps.who.int/iris/bitstream/ handle/10665/272596/9789241565585-ng.pdf?ua=1\&ua=1

2. Plagisou L, Tsironi M, Zyga S, Moisoglou I, Maniadakis N, Prezerakos P. Assessment of nursing staffs theoretical knowledge of cardiovascular resuscitation in an NHS public hospital. Hell J Cardiol. 2015;56(2):149-53. https://doi. org/10.1016/j.resuscitation.2016.07.089

3. Ciurzynski SM, Gottfried JA, Pietraszewski J, Zalewski M. Impact of Training Frequency on Nurses' Pediatric Resuscitation Skills. J Nurses Prof Dev. 2017;33(5):E1-7. https://doi.org/10.1097/nnd.0000000000000386

4. Boyde M, Wotton K. A review of nurses' performance of cardiopulmonary resuscitation at cardiac arrests. J Nurses Staff Dev. 2001;17(5):248-55. https://doi.org/10.1097/00124645-200109000-00008

5. Bukiran A, Erdur B, Ozen M, Bozkurt AI. Retention of nurses' knowledge after basic life support and advanced cardiac life support training at immediate, 6-month, and 12-month post-training intervals: A longitudinal study of nurses in Turkey. J Emerg Nurs. 2014;40(2):146-52. https://doi.org/10.1016/j.jen.2012.08.011

6. Miranda FBG, Mazzo A, Pereira Junior GA. Uso da simulação de alta fidelidade no preparo de enfermeiros para o atendimento de urgências e emergências: revisão da literatura (Use of high fidelity simulation in the preparation of nurses for urgency and emergency care: scoping review). Sci Med. 2018;28(1):ID28675. http://doi.org/10.15448/ 1980-6108.2018.1.28675.

7. Sullivan N. An integrative review: Instructional strategies to improve nurses' retention of cardiopulmonary resuscitation priorities. Int J Nurs Educ Scholarsh. 2015;12(1):1-7. https://doi.org/10.1515/ijnes-2014-0012

8. Brião RC, Souza EN, Castro RA, Rabelo ER. Estudo de coorte para avaliar o desempenho da equipe de enfermagem em teste teórico, após treinamento em parada cardiorrespiratória. Rev Lat Am Enfermagem. 2009;17(1):1-6. https://doi.org/10.1590/s0103-507x2006000200007

9. Hamilton R. Nurses' knowledge and skill retention following cardiopulmonary resuscitation training: a review of the literature. J Adv Nurs. 2005;51(3):288-97. https://doi.org/10.1111/j.1365-2648.2005.03491.x

10. Niles DE, Nishisaki A, Sutton RM, Elci OU, Meaney PA, O’Connor KA, Leffelman J, Kramer-Johansen J, Berg RA, Nadkarni V. Improved Retention of Chest Compression Psychomotor Skills With Brief "Rolling Refresher" Training. Simul Healthc J Soc Simul Healthc. 2017;12(4):213-29. https://doi.org/10.1097/sih.0000000000000228

11. Cecilio-Fernandes D, Cnossen F, Jaarsma DADC, Tio RA. Avoiding surgical skill decay: a systematic review on the spacing of training sessions. J Surg Educ. 2018; 75:471-80. https://doi.org/10.1016/j.jsurg.2017.08.002 
12. Kleinman ME, Brennan EE, Goldberger ZD, Terry M, Bobrow BJ, Gazmuri RJ, Travers AH, Rea T. Part 5: adult basic life support and cardiopulmonary resuscitation quality: 2015 American Heart Association Guidelines Update for Cardiopulmonary Resuscitation and Emergency Cardiovascular Care. Circulation. 2015;132:S414-S435. https://doi.org/10.1161/cir.0000000000000259

13. Travers AH, Perkins GD, Berg RA, Castren M, Considine J, Escalante R, Gazmuri RJ, Koster RW, Lim SH, Nation KJ, Olasveengen TM, Sakamoto T, Sayre MR, Sierra A, Smyth MA, Stanton D, Vaillancourt C; Basic Life Support Chapter Collaborators. Part 3: adult basic life support and automated external defibrillation: 2015 International Consensus on Cardiopulmonary Resuscitation and Emergency Cardiovascular Care Science With Treatment Recommendations. Circulation. 2015;132(suppl 1):S5-S83. https://doi.org/10.1161/cir.0000000000000272

14. Masarotto G, Varin C. Gaussian copula marginal regression. Electron J Stat. 2012;6:1517-49. https://doi.org/ $10.1214 / 12$-ejs 721

15. R Development Core Team. R: A Language and Environment for Statistical Computing. R Foundation for Statistical Computing, Vienna, Austria. Copenhagen: GBIEF; 2016.

16. Touloumis A, Agresti A, Kateri M. Generalized Estimating Equations for Multinomial Responses Using a Local Odds Ratio Parameterization. Biometrics. 2013;69(3):633-40. https://doi.org/10.1111/biom.12054

17. Gebremedhn EG, Gebregergs GB, Anderson BB, Nagaratnam V. Attitude and skill levels of graduate health professionals in performing cardiopulmonary resuscitation. Adv Med Educ Pract. 2017;8:43-50. https://doi. org/10.2147/amep.s114726

18. Jenkin AM. Nurses' attitudes to the teaching and training of cardio-pulmonary resuscitation. J Clin Nurs. 1994;3: 193-4. https://doi.org/10.1111/j.1365-2702.1994.tb00385.x

19. O’Donnell C. A survey of opinion amongst trained nurses and junior medical staff on current practices in resuscitation. J Adv Nurs. 1990;15:1175-80. https://doi.org/10.1111/j.1365-2648.1990.tb01710.x

20. Dane FC, Russell-Lindgren KS, Parish DC, Durham MD, Brown TD. In-hospital resuscitation: association between ACLS training and survival to discharge. Resuscitation. 2000; 47:83-7. https://doi.org/10.1016/s0300-9572(00)00210-0

21. Braslow A, Brennan RT, Newman MM, Bircher NG, Batcheller AM, Kaye W. CPR training without an instructor: development and evaluation of a video self-instructional system for effective performance of cardiopulmonary resuscitation. Resuscitation. 1997;34(3):207-20. https://doi.org/10.1016/s0300-9572(97)01096-4

22. Batcheller A, Brennan RT, Braslow A, Urritia A, Kaye W. CPR performance of subjects over forty is better following half-hour video self instruction compared to traditional four-hour classroom. Resuscitation. 2000;43(2):101-10. https://doi.org/10.1016/s0300-9572(99)00132-x

23. Cummins RO, Hazinski MF. Cardiopulmonary resuscitation techniques and instruction: when does evidence justify revision? Ann Emerg Med. 1999;34(6):780-4. https://doi.org/10.1016/s0196-0644(99)70105-8

24. Leary M, Abella B. The challenge of CPR quality: Improvement in the real world. Resuscitation. 2008;77:1-3. https://doi.org/10.1016/j.resuscitation.2008.02.005

25. Todd KH, Braslow A, Brennan RT, Lowery DW, Cox RJ, Lipscomb LE, Kellermann AL. Randomized, controlled trial of videos self instruction versus traditional CPR training. Ann Emerg Med. 1998;31:364-9. https://doi.org/ 10.1016/s0196-0644(98)70348-8

26. Mduma E, Ersdal H, Svensen E, Kidanto H, Auestad B, Perlman J. Frequent brief on-site simulation training and reduction in 24-h neonatal mortality: An educational intervention study. Resuscitation. 2015;93:1-7. https://doi.org/10.1016/j.resuscitation.2015.04.019

27. Barbosa GS, Bias CGS, Agostinho LS, Oberg LMCQ, Lopes ROP, Sousa RMC. Eficácia da simulação na autoconfiança de estudantes de enfermagem para ressuscitação cardiopulmonar extra-hospitalar: um estudo quase experimental (Effectiveness of simulation on nursing students' self-confidence for intervention in out-of-hospital cardiopulmonar resuscitation: a quase-experimental study). Sci Med. 2019;29(1):e32694. https://doi.org/10.15448/1980-6108.2019.1.32694

28. Nori, MJ, Saghafinia M, Motamedi MHK, Hosseini SMK. CPR training for nurses: how often is it necessary? Iran Red Crescent Med. J. 2012;14(2):104-7. 